Pacific Northwest National Laboratory

Operated by Battelle for the U.S. Department of Energy

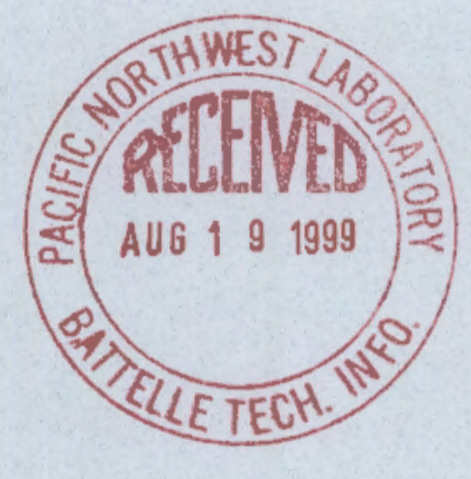

PNNL-12224

\title{
Assessment of Two Sulfur Lamp Retrofit Lighting Systems at the USPS Processing and Distribution Center, Portland, Oregon
}

\author{
E. E. Richman \\ M. L. Bruun
}

June 1999

Prepared for the U.S. Department of Energy

Federal Energy Management Program under Contract DE-AC06-76RLO 1830

Pacific Northwest National Laboratory

Richland, Washington 99352 


\title{
DISCLAIMER
}

This report was prepared as an account of work sponsored by an agency of the United States Government. Neither the United States Government nor any agency thereof, nor Battelle Memorial Institute, nor any of their employees, makes any warranty, express or implied, or assumes any legal liability or responsibility for the accuracy, completeness, or usefulness of any information, apparatus, product, or process disclosed, or represents that its use would not infringe privately owned rights. Reference herein to any specific commercial product, process, or service by trade name, trademark, manufacturer, or otherwise does not necessarily constitute or imply its endorsement, recommendation, or favoring by the United States Government or any agency thereof, or Battelle Memorial Institute. The views and opinions of authors expressed herein do not necessarily state or reflect those of the United States Government or any agency thereof.

\author{
PACIFIC NORTHWEST NATIONAL LABORATORY \\ operated by \\ BATTELLE \\ for the \\ UNITED STATES DEPARTMENT OF ENERGY \\ under Contract DE-AC06-76RLO 1830
}

Printed in the United States of America

Available to DOE and DOE contraetors from the

Ofice of Scientific and Technical Information, P.O. Box 62, Oak Ridge, TN 37831; prices available from (615) 576-8401.

Available to the public from the National Technieal Information Service, U.S. Department of Commerce, 5285 Port Royal Rd., Springfield, VA 22161 


\title{
Assessment of Two Sulfur Lamp Retrofit Lighting Systems at the USPS Processing and Distribution Center, Portland, Oregon
}

\author{
E. E. Richman
}

M. L. Bruun

June 1999

Prepared for the U.S. Department of Energy

Federal Energy Management Program

under Contract DE-AC06-76RLO 1830

Pacific Northwest National Laboratory

Richland, Washington 99352 



\section{Preface}

The mission of the U.S. Department of Energy's Federal Energy Management Program (FEMP) is to reduce the cost of govemment by advancing energy efficiency, water conservation, and the use of solar and other renewable technologies. This is accomplished by creating partnerships, leveraging resources, transferring technology, and providing training and technical guidance and assistance to agencies. Each of these activities is directly related to achieving requirements set forth in the Energy Policy Act of 1992 and the goals that have been established in Executive Order 13123 (June 1999), but also those that are inherent in sound management of Federal financial and personnel resources.

The Pacific Northwest National Laboratory (PNNL) supports the FEMP mission in all activity areas. This responsibility includes working with various Federal energy managers to identify, monitor, and evaluate the performance of new energy efficiency technologies suitable for installation at Federal sites.

This report provides the results of a field evaluation that PNNL conducted for FEMP and the U.S. Postal Service. The report examines the performance of a sulfur lamp technology using two different light distribution systems. The two lighting systems were installed as small test areas in the main mail processing room at the U.S. Postal Service Processing and Distribution Center located in downtown Portland, Oregon. Participating in this effort were the U.S. Postal Service, Portland General Electric (PGE), and PNNL. The lighting equipment was purchased and installed under a utility service agreement between the U.S. Postal Service and PGE, the utility that serves the site. Acting under the New Technology Demonstration Program, PNNL monitored the technology's installation process and the operating performance of the lighting systems. 



\section{Summary}

In 1998, a portion of the United States Postal Services Processing and Distribution Center in Portland, Oregon, was retrofitted with two similar sulfur lamp (S-lamp) lighting systems with hollow light guides as part of a project to test and evaluate the technology. S-lamps use microwave energy to produce a plasma that emits a high level of visible light across a broad color spectrum. The technology promises efficiency savings compared with conventional high intensity discharge lamps in comparable applications. Fusion Lighting, Inc., which developed the technology with assistance from the U.S. Department of Energy (DOE), Office of Building Technology, Community and State Programs (BTS), introduced the product as its Solar $1000^{\mathrm{TM}}$ lamp in 1994.

The hollow light guide is a light distribution method that uses light-refracting film to direct and distrihute light from a single source through a long tube that is able to cover a large area to be lighted. Two similar light guide products were installed in a side-by-side comparison for this test. One system was developed by $3 \mathrm{M}$ Corporation and is characterized by cylindrical sections of their own light-reflecting film material. The other system was developed by Cylinear Lighting and uses a $3 \mathrm{M}$ light-reflecting film product in a hexagonal shaped tube.

The test facility is located in an 8,700-square-foot portion of the second floor of the Processing and Distribution Center for the Portland regional area. The area has a low ceiling, requiring hollow light guides to distribute the high-intensity light with adequate uniformity. Six Solar $1000^{\mathrm{TM}}$ lamps were installed, one at each end of two double-ended light guides, and one in each of two single-ended light guides.

With support from the Federal Energy Management Program (FEMP), Pacific Northwest National Laboratory (PNNL) undertook to assess the efficiency and performance of the systems, as part of the New Technology Demonstration Program (NTDP). Both before and after installation, PNNL collected data characterizing lighting level and color, as well as electric energy consumption and power quality characteristics, for the two operating systems. PNNL also administered pre- and post-installation surveys of building occupant responses to gain insights into worker satisfaction with respect to the lighting system.

The following findings resulted from the assessment:

- The color characteristics of the retrofit sulfur lamp systems are closer to that of daylight than either the fluorescent or metal halide systems previously installed. 
- The amount of light provided to the critical work areas was reduced with the sulfur lighting systems alone. Additional task lighting installed along with the sulfur systems tended to match the level of lighting to the previous systems. The reduced light with the sulfur systems alone is brought about partially by the lack of effective placement of the sulfur systems. If the sulfur systems had been placed more directly in front of critical work areas, the required lighting levels would likely have been met. The use of only six Solar $1000^{\mathrm{TM}}$ lamps provided only $77 \%$ of the light output (total lumens) provided by the original systems, naturally leading to lower overall levels.

- The sulfur lamp systems by themselves could reduce lighting power in the test space by over $2.7 \mathrm{~kW}$ or 0.31 watts per square foot. However, these savings will not he achievable unless relocation of the systems can achieve the required lighting levels on critical work locations.

- The power quality of the sulfur systems is superior to other pre- and post-retrofit systems. The extremely low harmonics distortion and high power factor indicates that there should be no concerns with these systems in terms of building power supplies.

- There were no significant differences in the rating of the pre- and post-retrofit lighting systems by the occupants of the test space. Of the unique written comments received as part of the occupant surveys, many dealt with issues other than lighting. Some commenters indicated a preference for one system over another but there was no definite trend toward pre- or post-retrofit lighting. Several commenters noticed a harsh glare from the ends of the Cylinear system. This glare was confirmed with measured data.

- The installation process for both systems is similar in that botb use the same basic support structure. The Cylinear system, having longer sections, will generally require fewer support hangars, which may decrease installation costs. The $3 \mathrm{M}$ section clamping mechanism tends to create looser joints that may not seal adequately, while the Cylinear section clamping system is troublesome because it tends to rotate the section up to 15 degrees from vertical and causes faulty distribution of the light. Both $3 \mathrm{M}$ and Cylinear have promised improved connections in the future. The Cylinear section supports are easy to attach with a twist-andlock mechanism; the $3 \mathrm{M}$ sections require bolting. The $3 \mathrm{M}$ system with smooth surfaces all around is likely to be much easier to clean than the hexagonal section Cylinear system. 


\section{Acknowledgments}

The authors wish to acknowledge the support provided to this project by the site participants and others associated with the project. These include Les Fish, James Perkins, and Margaret Grey of the U.S. Postal Service, Lark Lahart of Portland General Electric, and Steve Parker and Dave Payson of PNNL. The authors would also like to thank the FEMP Utility Service Program and New Technology Demonstration Program for their programmatic support of this technology demonstration. 



\section{Contents}

Preface

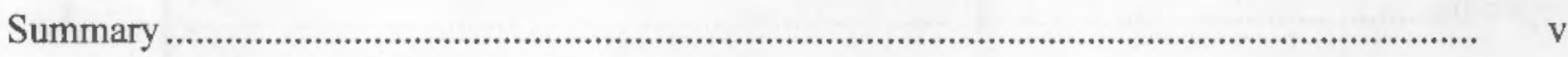

Acknowledgments............................................................................................................... vii

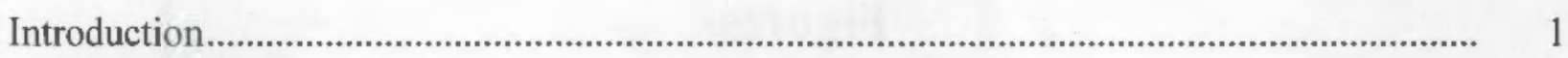

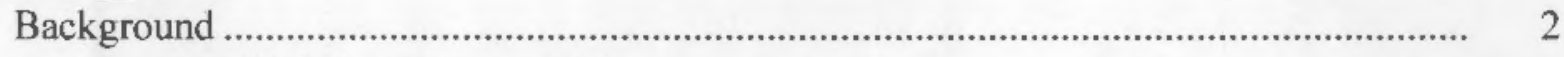

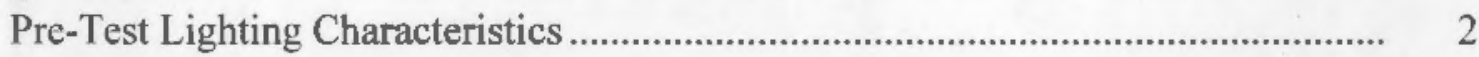

Test Setup Characteristics ................................................................................ 3

Sulfur Lamp Development ................................................................................... 3

Light Guide Development .......................................................................................

Data Collection and Survey Administration .......................................................................

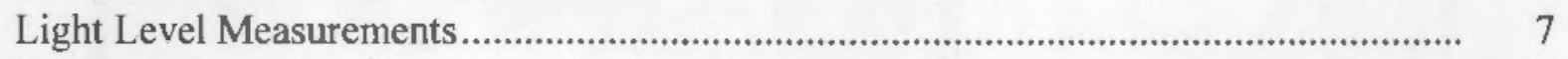

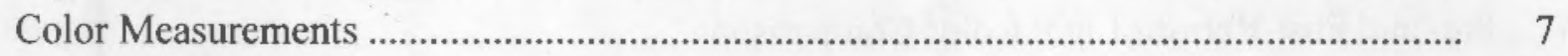

Power Consumption ................................................................................................. 7

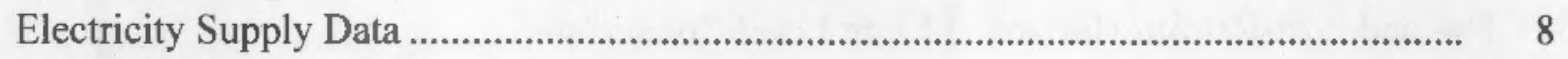

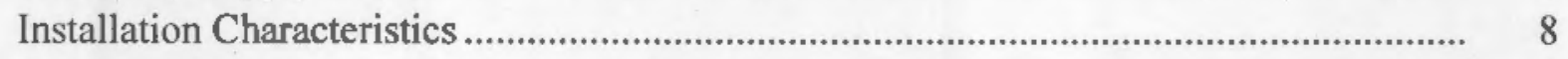

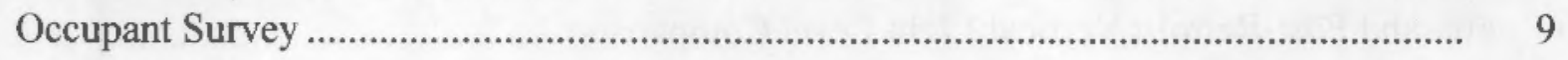

Color Comparison of Pre- and Post-Retrofit Lighting Systems ............................................... 11

Light Level Comparison of Pre- and Post-Retrofit Lighting Systems......................................... 13

Power Consumption Comparison of Pre- and Post-Retrofit Systems ........................................ 17

Electricity Supply Comparison of Pre- and Post-Retrofit Lighting Systems .......................... 19

Installation and Product Characteristics of the Two Systems...................................................... 21

Product Integrity and Function..................................................................................... 21

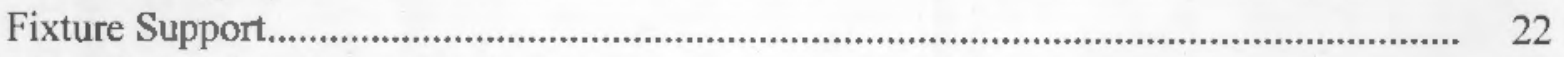

Light Guide Attachment Methods to Supports .............................................................. 22

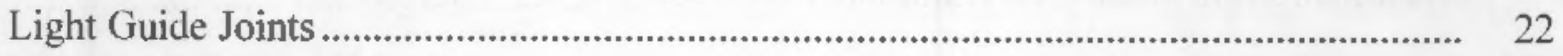

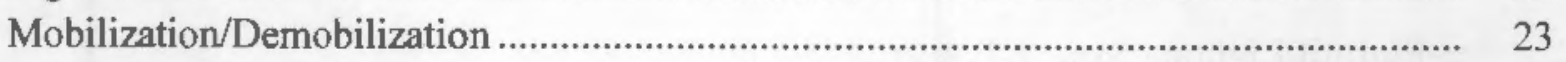

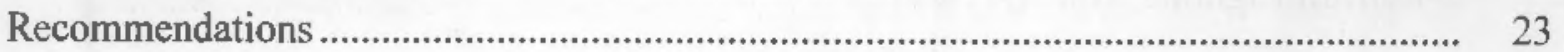


Occupant Survey of Pre- and Post-Retrofit Lighting Conditions ............................................. 25

Comments .................................................................................................................. 27

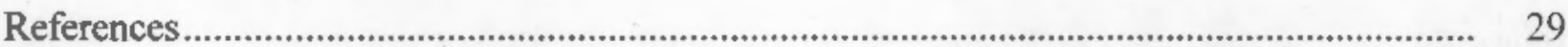

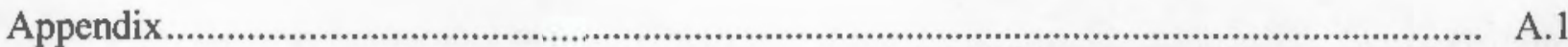

\section{Figures}

1 Pre-Retrofit Lighting System (looking toward main aisle) ................................................. 2

2 Pre-Retrofit Lighting System (looking toward exterior wall) ............................................. 3

3 Typical Floor and Specific Machine Measurement Locations............................................ 8

4 Pre- and Post-Retrofit Light Color Comparison ……....................................................... 12

5 Pre- and Post-Retrofit Horizontal Light Level Comparison ............................................... 13

6 Pre- and Post-Retrofit Vertical Light Level Comparison.................................................... 14

$7 \quad$ Post-Retrofit Light Guide Placement - Example 1 1.......................................................... 15

$8 \quad$ Post-Retrofit Light Guide Placement - Example 2 2............................................................. 15

9 Post-Retrofit Light Guide Output Consistency …….......................................................... 16

\section{Tables}

1 Comparison Light Guide End Luminance ………....................................................... 16

2 Pre-Retrofit Lighting System Power ........................................................................ 17

$3 \quad$ Post-Retrofit Lighting System Power .......................................................................... 17 
4 Pre- and Post-Retrofit Electrical Supply Characteristics .................................................... 19

5 Comparison of Lighting-Related Characteristies ................................................................ 25

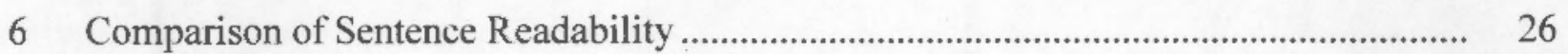

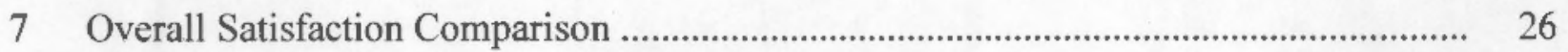




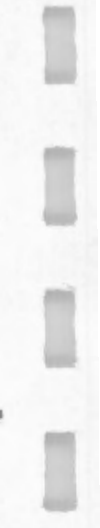<smiles>C1CCCC1</smiles><smiles>[C]1CCCC1</smiles><smiles>C1CCCC1</smiles><smiles>C1CCC1</smiles><smiles>C1CCCC1</smiles><smiles>c1ccccc1</smiles><smiles>[124IH]</smiles><smiles>[CH]1[CH]CC1</smiles><smiles>[C]1CCCC1</smiles>

8

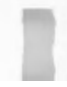




\section{Introduction}

This report presents the results of an assessment of a test installation of two similar sulfur lamp, or S-lamp lighting systems, with hollow-light guide distribution. The S-lamp, developed by Fusion Lighting, Inc. with support from the U.S. Department of Energy (DOE), Office of Building Technology, Community and State Programs (BTS), was demonstrated as a prototype for the first time in 1994. The S-lamp embodies a new, microwave-powered, electrodeless technology that offers improved energy efficiency and color rendition compared with most available sources. The purpose of this assessment is to provide important information to all of those involved regarding the effectiveness and future applicability of this technology in a postal sorting setting.

The United States Postal Service (USPS) Processing and Distribution Center initially contracted the local service utility, Portland Gas and Electric (PGE), to provide contracting and oversite services for this retrofit test project. PGE enabled the installation of this technology as a part of their interest in potentially supporting this lighting technology in their service area. They initiated the statement of work and administered the installation contract. The USPS purchased the equipment and provided access to their facility in order to gain insight into the applicability of this technology in other similar facilities. The Department of Energy's Federal Energy Management Program (FEMP), as part of its New Technology Demonstration Program (NTDP), involved the Pacific Northwest National Laboratory (PNNL) in providing analysis of the test installation. FEMP is then able to provide this information to federal agencies and others who may be interested in advanced lighting technology application.

The two different hollow light guide systems installed in this test case were developed by $3 \mathrm{M}$ Corporation and Cylinear Lighting. Each uses a form of light refraction film developed by $3 \mathrm{M}$ Corporation as a means of transmitting light through a space for distribution across a wide area.

In 1998, the Portland USPS Processing and Distribution Center initiated a contract with PGE to purchase and installed two hollow light guides from the 3M Corporation and two from Cylinear. Each guide was fitted with Fusion Lighting's Solar $1000^{\mathrm{TM}}$ lamps. Because this was a small test case, the original metal halide and fluorescent lighting was retained wherever possible in case it was to be used again. In order to provide quantifiable information for those considering installing either technology, the USPS undertook, through the efforts of PNNL, to obtain data characterizing the effeetiveness and applicability of the two systems. This characterization and analysis covered lighting quantity and quality of the retrofit and existing systems, including energy use, power quality, light levels, color rendering, and human responses. An assessment 
was also made of the installation requirements and activities with respect to both systems to determine any critical differences and efficiencies.

The report begins with a brief summary of the history of sulfur lamp technology and highlights the features of the first commercial product, the Solar $1000^{\mathrm{TM}}$. It then discusses the technology and characteristics of the associated hollow light guide technologies of each of the two different systems. The remainder of the report is devoted to the analysis of the two installed systems.

\section{Background}

\section{Pre-Test Lighting Characteristics}

The test area for evaluating the two sulfur lamp hollow light guide systems covers an area between columns 10 and 12 on the second floor of the processing and distribution center. This area is approximately 8,700 square foot in size and is divided into two sections by a main aisleway. The activities in this area are typical of current technology mail sorting functions and considered representative of a large portion of USPS workspace.

The original overhead lighting in this space consisted of fluorescent industrial strip lighting on one side of the main aisle and metal halide downlights on the other. Both sides of the main aisle also had some additional fluorescent strip task lighting over critical maintenance areas. Figures 1 and 2 show the pre-retrofit conditions.

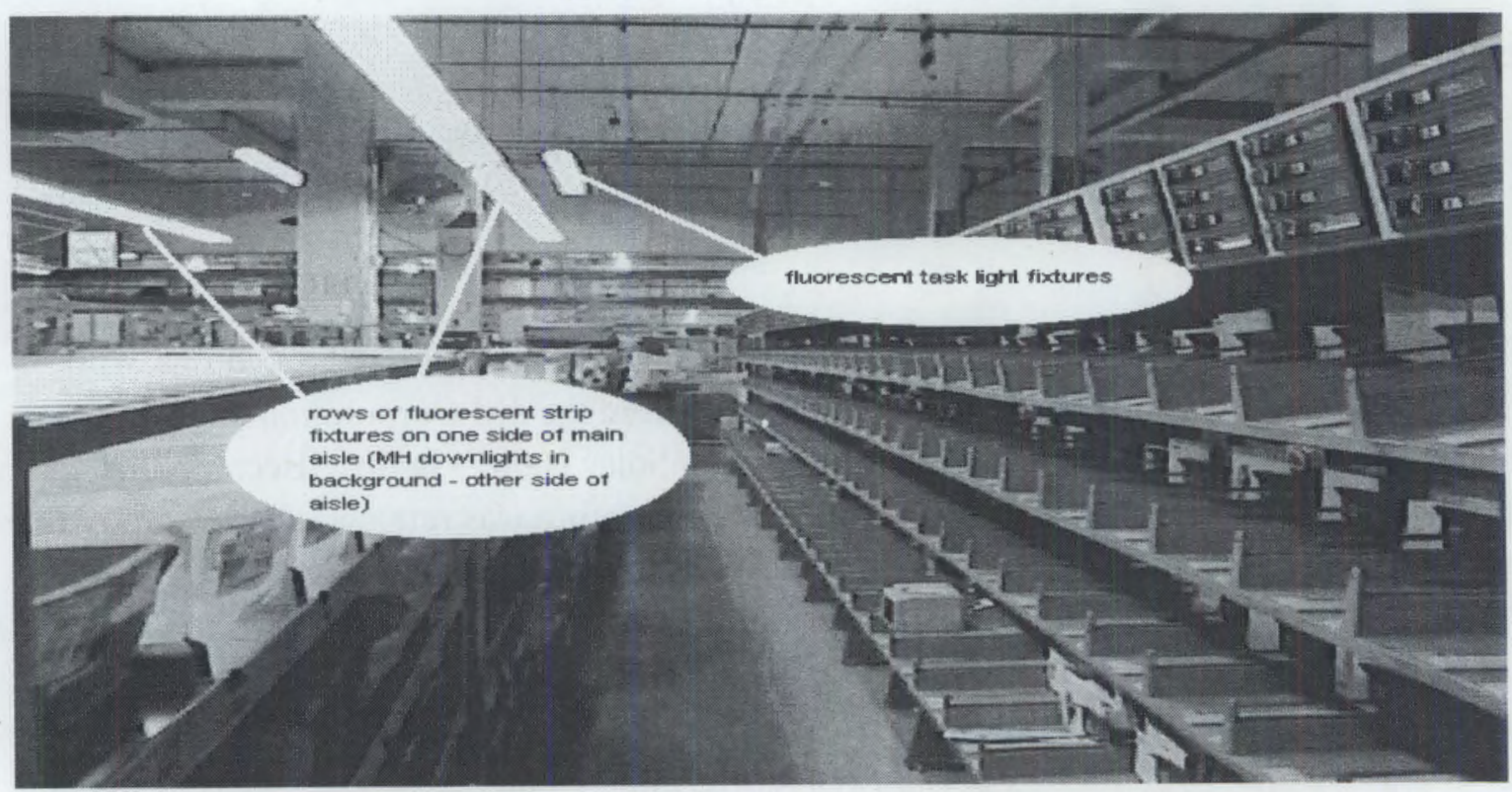

Figure 1. Pre-Retrofit Lighting System (looking toward main aisle) 


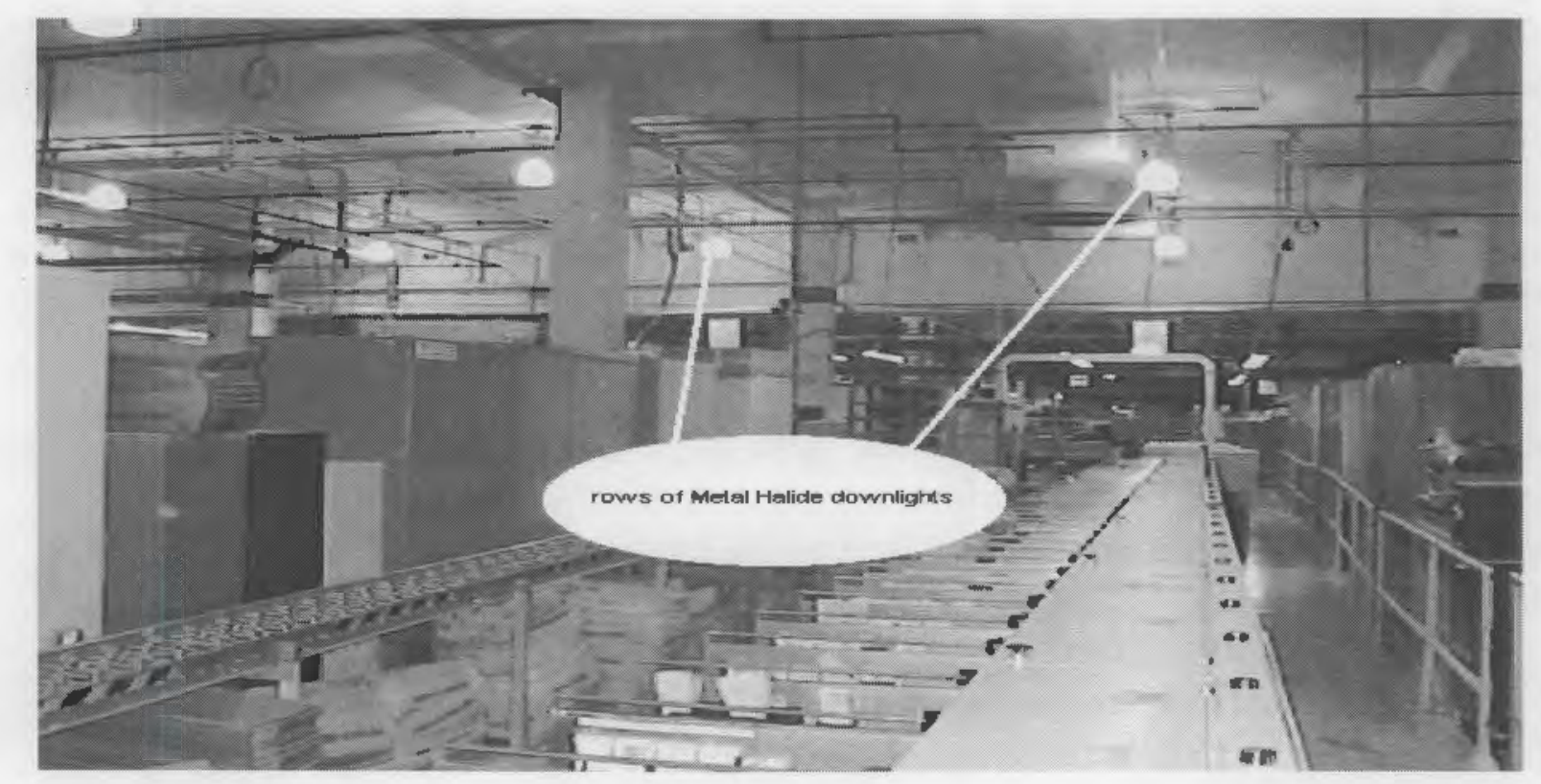

Figure 2. Pre-Retrofit Lighting System (looking toward exterior wall)

\section{Test Setup Characteristics}

The installation of the new sulfur lamp/light guide installation included two 3M light guide systems and two Cylinear light guide systems. One of each type of system was installed on each side of the main aisleway. This resulted in the two competing systems being installed parallel to each other across the test area. On one side of the aisle, the light guide systems were each 80 feet long powered with two Solar $1000^{\mathrm{TM}}$ lamps. The systems on the other side were 50 feet long and powered by only one Solar $1000^{\mathrm{TM}}$ lamp. The fact that the test area is small and that the competing systems are in close proximity to each other creates some difficulty in gathering useful lighting measurements of the new retrofit lighting. Light "spillover" from older lighting left in place in neighboring areas on both sides of the test area and the mixing of light from both new retrofit systems on areas between the systems will tend to reduce the effective comparison of the systems by themselves.

\section{Sulfur Lamp Development}

Using microwave energy to produce a sulfur plasma that emits a high level of visible light was first introduced in 1992. ${ }^{1}$ Prior to this time microwave discharges were used to produce ultraviolet (UV) light for industrial applications but had not been applied to producing visible light. The research up until that time had not indicated that output of the visible spectrum would occur with the sulfur. Additional searches of the literature indicated that other researchers had explored the use of sulfur in electrodeless discharges but found efficiencies in the $11-13 \%$ range. However, current sulfur source developed by Fusion lighting has an efficiency of around $50 \%$. 
In this application, prototype spheres were filled with sulfur to approximately 10 atmospheres and bombarded with the microwaves from the Fusion microwave system. The high-pressure sulfur vapor formed the plasma medium that produced visible light by molecular radiation.

The work on understanding the mechanisms and phenomenon of producing a broad-spectrum visible light with microwave energy has progressed rapidly. Initially, the efficiency of producing light by this method was questioned because of the low efficiencies of the existing magnetrons and the associated equipment for producing the microwave energy. Work has progressed through several stages to arrive at the current technology. Demonstration installations have been made with high power ( $>3 \mathrm{~kW}$ microwave power) at the Smithsonian National Air and Space Museum (NASM), DOE's Forrestal Building, and in a repair hangar at Hill Air Force Base, Utah.

The development of the technology has progressed rapidly and is continuing to be refined. The application of the S-Lamp system technology to different spaces is a logical step in the development and commercialization. Possible applications include sports lighting, large retail stores, shopping malls, manufacturing facilities, assembly lines, subways, and tunnels.

The most recent version of this lamp, the Solar $1000^{\mathrm{TM}}$, produces nearly 150,000 lumens with a system input power of 1350 watts. The Solar $1000^{\mathrm{TM}}$ uses a fill of sulfur and argon gas and is sealed in a glass bulb approximately $38 \mathrm{~mm}$ in diameter. The bulb is mechanically rotated to reduce heat buildup as it is excited by microwave energy producing a plasma that emits highintensity visible light. The current observed efficacies are approximately 170 lumens per microwave watt and demonstrated whole system efficacies of approximately 110 lumens per watt. The S-Lamp whole system efficacy accounts for the losses in the microwave generator and the associated electronic components. In order to compare the Solar $1000^{\mathrm{TM}}$ with the metal halide and high-pressure sodium HID lamps, the whole system efficaey must be used due to the difficulty in measuring power delivered directly to an electrodeless lamp.

The predicted life of the S-Lamp is based on the electronic components and not the lamp bulb itself. The life of the current technology microwave magnetron is projected at approximately 15,000 hours, while the life of the bulb should be considerably longer. The other components in the system that may fail include the ballast, transformer, and motor that rotates the bulb. The bulb, being electrodeless, results in very low lamp lumen depreciation.

\section{Light Guide Development ${ }^{2}$}

In present applications, the S-Lamp source has generally been coupled with a hollow light guide as a distribution medium for the high lumen output of the Solar $1000^{\mathrm{TM}}$. The use of hollow light guides has a long history. A hollow light guide is essentially an internally mirrored 
tube that will transport light from a source to another location. A surge of work occurred in the 1880 s with the advent of the high power electric carbon arc lamps, but there were problems with the fabrication and expense of the mirrors used in the system. The problem became expense and the efficiency of the mirrors. Over several years, new developments in materials yielded partial solutions to the problems. First was the development of a solid dielectric guide with high efficiency using total internal reflection (TIR), which had no absorption of the reflected light rays like the metallic mirrors. A second development involved the application of data from a 1946 publication by Henry Pearson of the Rohm and Haas Company describing the use of acrylic rods and sheets. These materials would allow light to be emitted continuously from them. However, it was noted that it was difficult to inject enough light to make them useful. The improvement in optical fibers and the advent of inexpensive high-quality polymeric films allowed further development. In 1965 in the former Soviet Union, the use of a metallic mirrored hollow light guide was proposed and work continued, and it was patented in 1975 . Eventually over 47,000 of these devices were installed.

In 1978, Loren Whitehead at the University of British Columbia developed the concept of a hollow light guide utilizing total internal reflection rather than metallic mirrors. This device was called the prism light guide, which used transparent walls that contain right angle prisms such that light rays continue propagating along the guide. In 1983, these devices went into manufacturer and have been used in North America, Japan, and Europe. They are used in many different applications with sources ranging from 50 watts to 100,000 watts. What allowed this growth was the development of precision prismatic film by $3 \mathrm{M}$ Corporation in St Paul, Minnesota. The precise prisms required in the walls of the light guides were a significant problem to properly produce and control and resulted in excessive manufacturing costs. The advent of the prismatic film in 1985 made it practical to produce large prismatic structures that serve as hollow light guides. The development of the hollow light guide continues and at least 15 organizations offer or are developing fixtures for various applications. The size and intensity of the S-Lamp system makes it an ideal source for use with these light distribution devices. 



\section{Data Collection and Survey Administration}

The function, effectiveness, and operational characteristics of the pre- and post-retrofit lighting systems in the mail sorting area were defined by specific measured electrical and lighting characteristics data points as well as occupant reactions. These data were used to identify and quantify differences between the systems that would assist energy managers in determining the effectiveness of an application of this new technology in their facilities. Each lighting system was characterized with color measurements, light level measurements, power consumption, and electricity supply data. An occupant survey was also administered to gauge the experience of the occupants with respect to both lighting systems.

\section{Light Level Measurements}

Light level readings (in foot-candles) were taken at floor level and at specific vertical and horizontal work surfaces throughout the test space. Each of these sets of measurements was taken at specific points on a grid covering the test area. The test area covers a total of over 8,700 square feet with over 200 floor measurement points and 33 vertical and horizontal measurement points on work surfaces. Figure 3 shows the format for these measurements. Measurements were taken with a Minolta T-1 illuminance meter. Luminance (light output intensity from the light source) measurements were also taken across and directly below each type of light guide to determine uniformity. The luminance while viewing the end of each pipe was also measured to assess source glare. These measurements were taken with a Photo Research Litemate III with Spotmate attachment.

\section{Color Measurements}

Color measurements consisted of measurements of the true color of the light sources above the sorting equipment. The measurements were taken with a Minolta Chroma Meter CL-100 in units of Commission Internationale de l'Eclairage (CIE) $u$ ' and v'. These units are used with the 1976 CIE chromaticity diagram in placing the color of a similar brightness object with respect to others.

\section{Power Consumption}

The measurement of the complete lighting system at one metering point was not possible with the existing configuration of the multiple lighting and mixed panels. In place of this, the measurements were taken for several circuits with amounts and types of existing lighting known for that circuit. This data along with accurate lamp type and quantity counts enabled the 


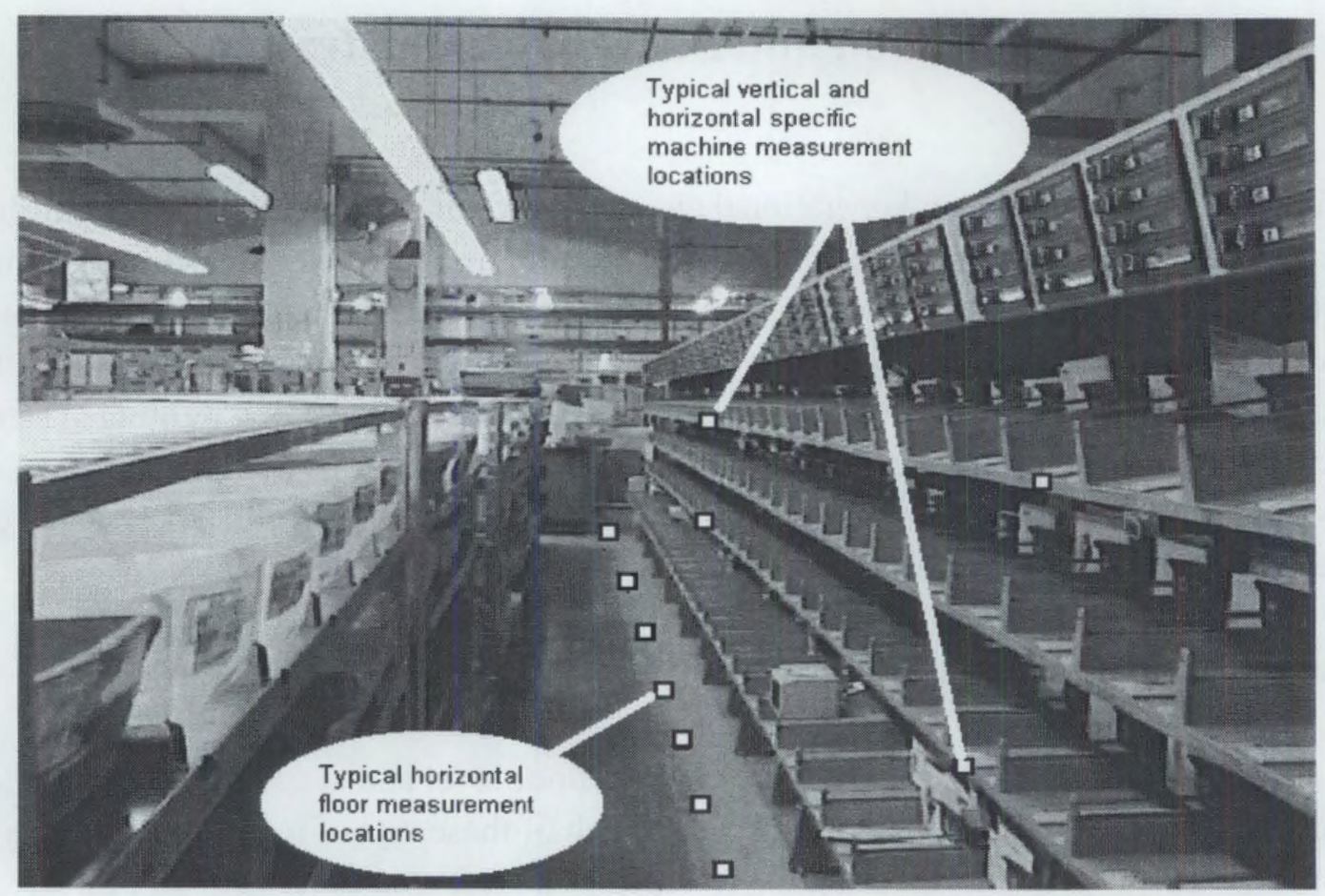

Figure 3. Typical Floor and Specific Machine Measurement Locations

calculation of an estimated total power consumption value for the test space. Power consumption was measured with a Fluke 41 power harmonics analyzer.

\section{Electricity Supply Data}

Other characteristics of the lighting electrical supply were also measured to understand any potential differences in the effect of the lighting systems on the facility power supply. The same Fluke 41 analyzer was used to collect root mean square voltage and current (RMS), crest factor (CF), total harmonic distortion (THD_F), and power factor (PF).

\section{Installation Characteristics}

The ease and effectiveness of the installation of each retrofit system was also a concern of the USPS facility for application in other areas and facilities. An assessment was made of the installation process during the actual installation and adjustment of both systems. This included characterization of the process, materials, and general applicability of the process to other situations. 


\section{Occupant Survey}

A survey of the workers in the sorting space was used to try and identify any effect the lighting retrofit may have had on the occupants and their operations. The dependent variahles that are of concern in this evaluation generally fall under the categories of visual effectiveness and visual satisfaction. These variables relate to how effective the lighting is and how well accepted it is by the occupants. The independent variable in this evaluation that will potentially affect user behavior and job satisfaction is the lighting type (existing lighting vs. Solar $1000^{\mathrm{TM}}$ lamp system). The measure for this study is a seven point self evaluation questionnaire filled out by subjects on a pre- and post-retrofit basis.

The questions the subjects respond to cover brightness, reflections, glare, physical discomfort associated with the eye, suitability of the light for the tasks they perform. See the Appendix for a complete copy of the lighting survey questionnaires.

The survey was distributed by USPS staff to all of the workers assigned to operations in the test space. The confidentiality of the occupant responses is maintained through a coding system to ensure there are no concerns over potential misuse of the response information. This coding also provides the means of matching specific before and after responses. Prior to the retrofit of the existing lighting, a letter of introduction and explanation of the survey was distributed by USPS staff to the selected occupants. This letter requested their voluntary participation in the survey and included the survey form for their response. After the retrofit, the survey was administered again to the same potential group of occupants to get their response to the new lighting system. 


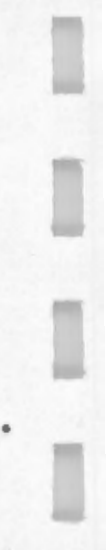

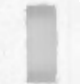

I

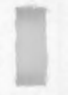

1]

[

(1)

I

(1)

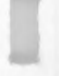

(1)

I

1

I

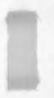

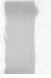




\section{Color Comparison of Pre- and Post-Retrofit Lighting Systems}

The pre-retrofit lighting systems (fluorescent and metal halide) provide reasonable color for the purposes of mail sorting activities. However, metal halide sources are known to experience wide color shifts over their life, creating variation in source color appearance. The post-retrofit Solar $1000^{\mathrm{TM}}$ lighting system has so far not shown any signs of this type of characteristic light source shift. It is also reported to provide even hetter quality light than metal halide sources in terms of emitting closer to the full spectrum of light generally associated with daylight. Figure 4 shows a representation of the measured Commission Internationale de l'Eclairage (CIE) 1976 ( $\left.u^{\prime}, v^{\prime}\right)$ coordinates for pre-retrofit, post-retrofit, and several standard lighting technologies. This representation is not an exact determination of actual perceived color but does provide a universally recognized measure of the relative color of each system with respect to other known lighting systems. The figure includes representations of the following:

$$
\begin{array}{ll}
\text { under FL } & =\text { pre-retrofit T8 fluorescent lighting } \\
\text { under MH } & =\text { pre-retrofit metal halide lighting } \\
\text { Cylinear } & =\text { post-retrofit sulfur lamp with Cylinear light guide } \\
\text { 3M } & =\text { post-retrofit sulfur lamp with 3M light guide } \\
\text { CW } & =\text { standard "cool white" fluorescent lighting } \\
\text { MH } & =\text { standard "metal halide" lighting } \\
\text { Mercury } & =\text { standard "mercury vapor" lighting } \\
\text { HPS } & =\text { standard "high pressure sodium" lighting } \\
\text { LPS } & =\text { standard "low pressure sodium" lighting } \\
\text { Daylight } & =\text { typical daylight conditions. }
\end{array}
$$

The close grouping of these plotted points indicates that both pre- and post-retrofit systems provide similar coloring on surfaces. All four systems provide lighting that is farther from the generally orange-yellow poor coloring associated with high and low pressure sodium sources and closer to typical daylight. The post-retrofit sulfur systems provide the hest quality, being even closer to typical daylight. The standard mercury vapor source also appears to be relatively close to preferred daylight coloring, but the low efficiency of this source and its tendency toward a "greenish" hue generally preclude it from consideration in most current lighting design. 


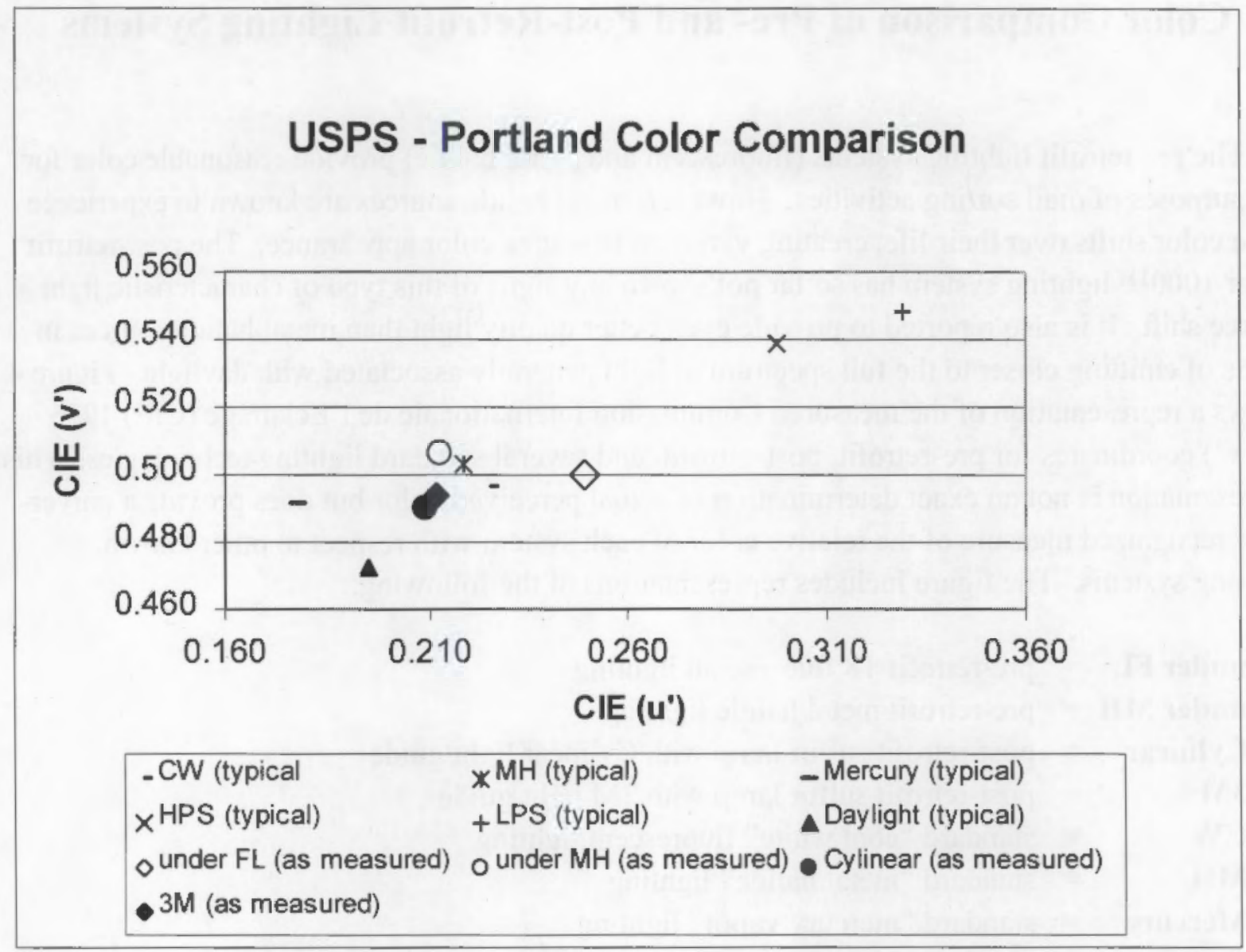

Figure 4. Pre- and Post-Retrofit Light Color Comparison 


\section{Light Level Comparison of Pre- and Post-Retrofit Lighting Systems}

Horizontal light level measurements were taken at floor level across the test area between machines and in walkway areas. These measurements would normally be able to provide a reasonable comparison of effective pre- and post-lighting. However, the nature of the mail sorting includes many tall sorting machines with vertical bins and constantly moving carts, and these conditions render low floor measurements relatively ineffective. During the collection of this data it was noted that the shadows caused by the moving carts made it impossible to achieve a consistent before-and-after set of measurements.

Vertical and horizontal light level measurements were also taken at specific work locations on the sorting machines (DBCS-40, $-41,-52,-53$ ). Many of these locations were high enough to be above the carts and were therefore able to better represent the lighting conditions from the location and characteristics of the overhead lighting systems. Figures 5 (horizontal) and 6 (vertical) each show comparisons of three sets of lighting measurements on specific machine locations. Each location includes a measurement of the original metal halide or fluorescent lighting, the sulfur lighting retrofit with the additional fluorescent task lighting that was installed at the same time, and the sulfur lighting retrofit only.

Both figures indicate that with the retrofit sulfur lamp only (none of the additional installed task lighting on), the lighting levels in most locations are lower than with the original lighting in the space. This is consistent with the fact that the total lumens of light supplied by the sulfur lamps alone is only approximately $77 \%$ of the total lumens supplied by all of the original lamps.

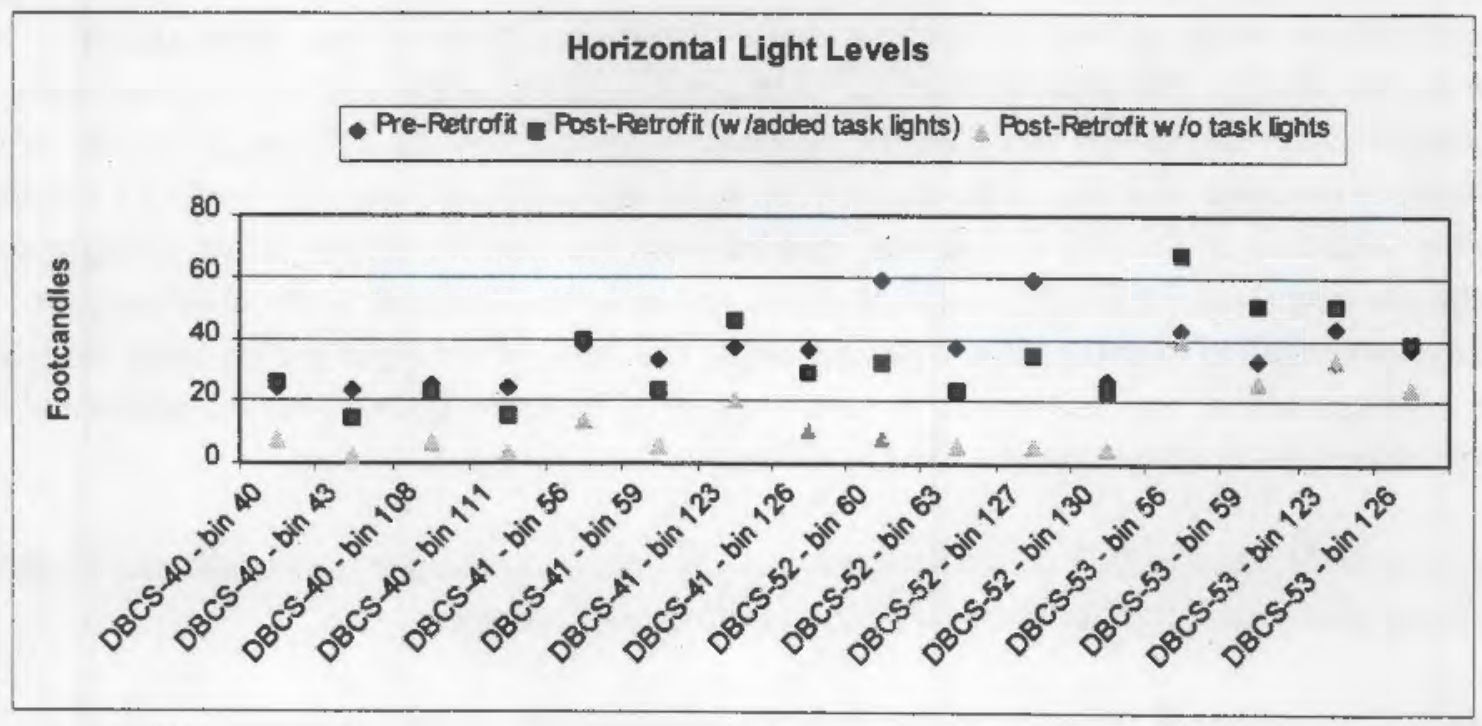

Figure 5. Pre- and Post-Retrofit Horizontal Light Level Comparison 


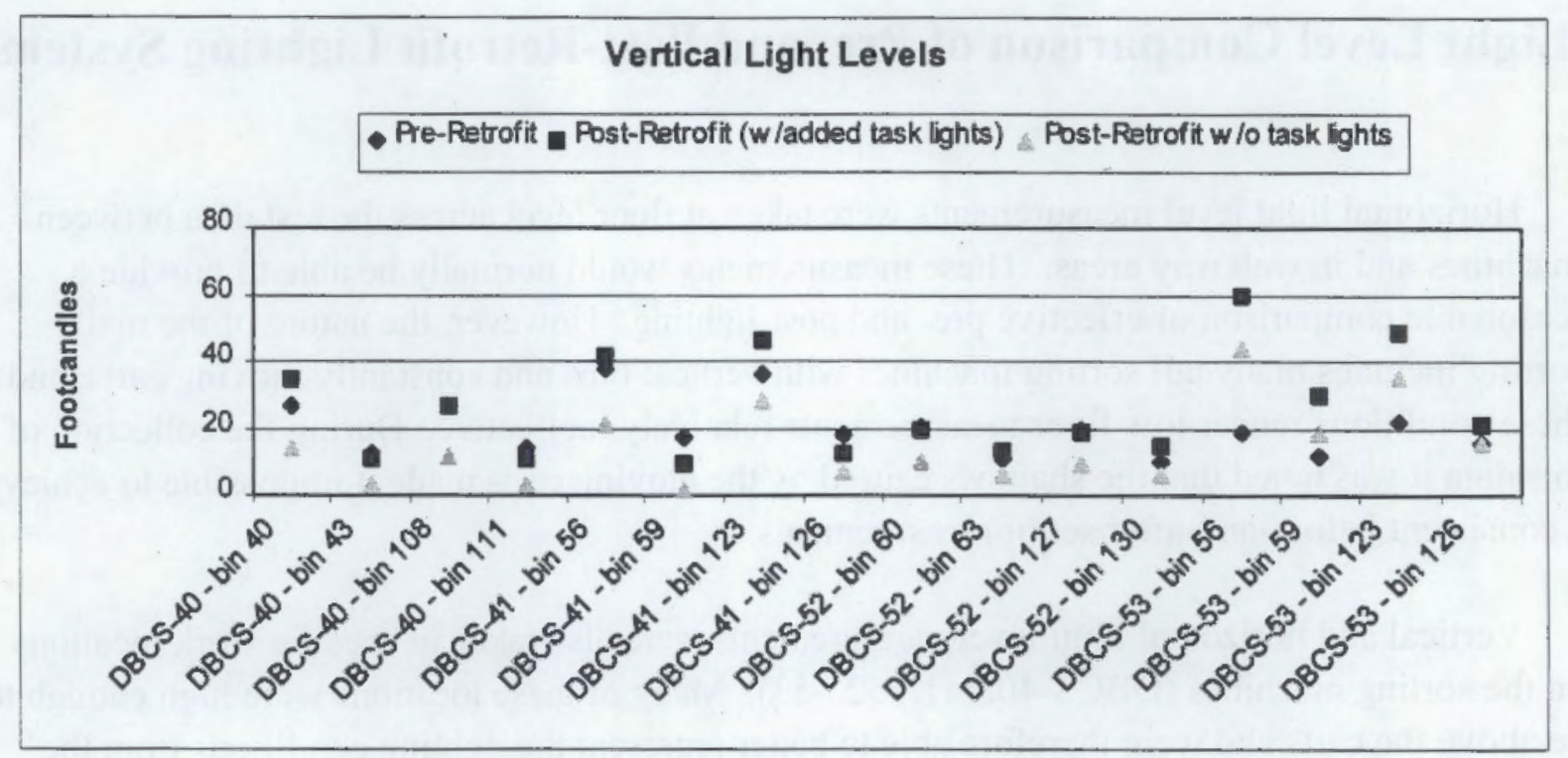

Figure 6. Pre- and Post-Retrofit Vertical Light Level Comparison

With the additional task lighting added with the retrofit, the lumens delivered by the total retrofit plus task lighting is approximately $15 \%$ more than the original lighting. This is also seen in both figures where the pre- and post-retrofit light level values are generally consistent with some specific locations showing large increases or decreases.

The sulfur lighting systems are by their design more concentrated than other lighting systems. In the case of this retrofit, there could have been noticeable increases in lighting levels on specific work locations if the sulfur light guide systems had been oriented more directly above the machinery. The placement of the light guide systems in this facility was somewhat hampered by other equipment and security galleries. Figure 7 shows a light guide system (center lighted tube) installed over the walkway between some movable carts and the back of a sorting machine. The front of the sorting machine (hidden from view on the left) is primarily lighted with the additional row of task lights (lighted row on the left). Figure 8 shows another light guide system installed over the back walkway of the machine on the right hut far from the front of the sorting machine bins on the left. Again the sorting bins are lighted with the additional strip of fluorescent task lighting installed to the left of the light guide system.

A set of light-level-related measurements was also taken to evaluate the consistency of the light output along each light guide system and is shown in Figure 9.

These data indicate that both systems show some variability. The $3 \mathrm{M}$ guide shows a very high value directly on the middle section where the distributed light of the sulfur lamps at each 


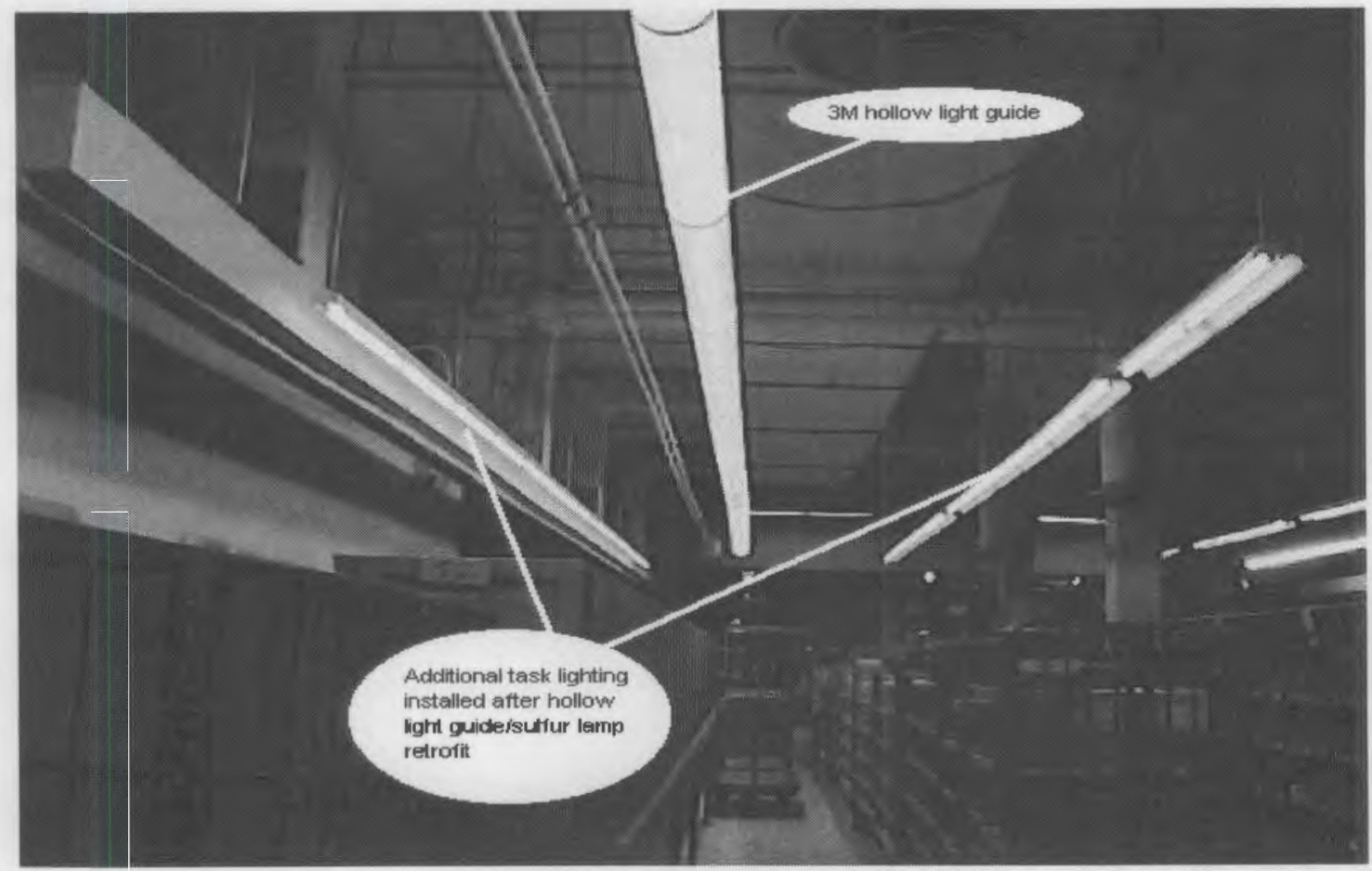

Figure 7. Post-Retrofit Light Guide Placement - Example 1

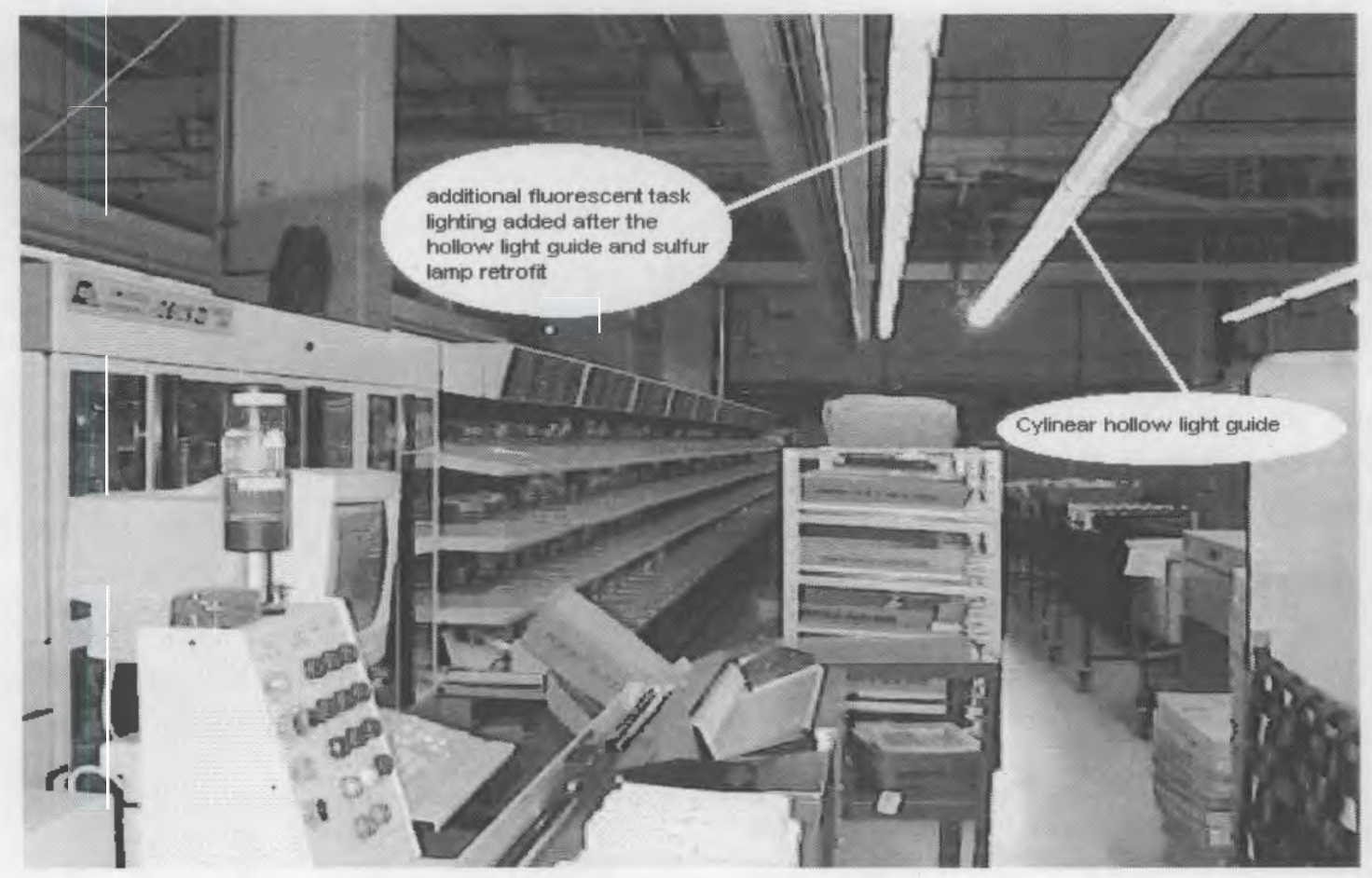

Figure 8. Post-Retrofit Light Guide Placement - Example 2 


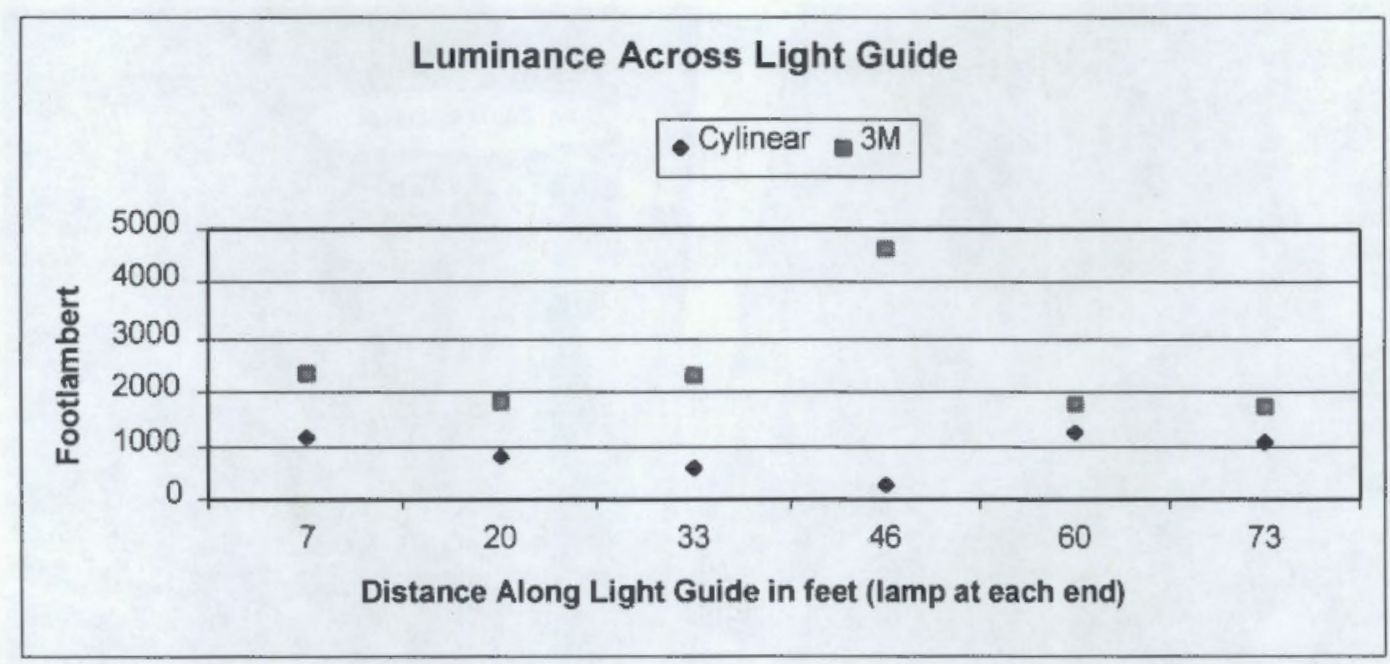

Figure 9. Post-Retrofit Light Guide Output Consistency (measurements taken directly underneath light guide)

end of the guide would meet. The Cylinear pipe shows a fairly drastic drop in output towards the middle. This output drops to nearly $25 \%$ of the average for the guide. It appears from the figure that the $3 \mathrm{M}$ guide produces more intensity across the entire guide. However, this may be due to the misalignment or rotation of the Cylinder guide noted in the installation characteristics notes.

A final set of light-level measurements was taken to address the concern noted by some postal workers that the Cylinear light guide exhibited very strong glare at the ends of each light guide. Measurements were taken of the luminance of each end of both Cylinear and $3 \mathrm{M}$ light guides while standing at the direct center of the guide. These measurements, shown in Table 1, mimic the view the workers experience during their workday.

Note that the average Cylinear end luminance is six times that of the $3 \mathrm{M}$ light guide and typically six times that of its own luminance across its length (Figure 7). This confirms the extreme glare noticed at the site. Because the viewing size of the end of the light guide was slightly smaller than the viewing aperture of the luminance measurement instrument, the values in Table 1 cannot be considered to be true measurements of exact footlamherts but are reasonable in showing the relative difference in the two installations.

Table 1. Comparison Light Guide End Luminance (footlamberts)

\begin{tabular}{|l|c|c|c|}
\hline \multicolumn{1}{|c|}{ Light Guide } & End 1 & End 2 & Average \\
\hline \hline $3 \mathrm{M}$ & 1194 & 877 & $\mathbf{1 0 3 6}$ \\
\hline Cylinear & 9490 & 3370 & $\mathbf{6 4 3 0}$ \\
\hline
\end{tabular}




\section{Power Consumption Comparison of Pre- and Post-Retrofit Systems}

The power consumption measurements were made for representative lighting circuits where quantities and types of lamps were known. From these data, extrapolations of energy use based on lamp counts and identification could be made. The lamp counts of the pre-retrofit system identified a total of 12 working Metal halide lamps and 170 4-foot, 32-watt, T8 (F32T8) fluorescent lamps. The energy consumption of specific circuits was used to algebraically determine an estimated operational wattage for each fixture type. These values were used to estimate the total wattage for the test area. Tables 2 and 3 show the lamp counts, measured lamp power total connected power, and lamp lumen output for the pre- and post-retrofit conditions.

Table 2. Pre-Retrofit Lighting System Power

\begin{tabular}{||c|c|c|c|c||}
\hline Lamp Type & Average Measured Wattage & Count & Total $\mathrm{kW}$ & Lumens \\
\hline \hline West Side \\
\hline F32 T8 & 30.6 & 20 & 0.61 & 72,000 \\
\hline Metal halide & 456 & 12 & 5.47 & 432,000 \\
\hline East Side & 150 & 4.59 & 540,000 \\
\hline F32 T8 & 30.6 & $\mathbf{1 0 . 6 7}$ & $\mathbf{1 , 0 4 4 , 0 0 0}$ \\
\hline
\end{tabular}

Table 3. Post-Retrofit Lighting System Power

\begin{tabular}{|c|c|c|c|c|}
\hline Lamp Type & Average Measured Wattage & Count & Total kW & Lumens \\
\hline \multicolumn{5}{|l|}{ West Side } \\
\hline Solar $1000^{\mathrm{TM}}$ & 1323 & 2 & 2.65 & 270,000 \\
\hline Alto $\mathrm{T} 8$ & 22.4 & 20 & 0.45 & 72,000 \\
\hline Metal halide & 456 & 3 & 1.37 & 108,000 \\
\hline \multicolumn{5}{|l|}{ East Side } \\
\hline Solar $1000^{\mathrm{TM}}$ & 1323 & 4 & 5.29 & 540,000 \\
\hline Alto $\mathrm{T} 8$ & 22.4 & 64 & 1.43 & 230,400 \\
\hline \multicolumn{3}{|c|}{ Total Post-Retrofit } & 11.19 & $1,220,400$ \\
\hline \multicolumn{3}{|c|}{ [Without T8 task lights } & 7.94 & $810,000]$ \\
\hline
\end{tabular}


Without the additional fluorescent task lighting installed as part of the retrofit, the power consumption for the retrofit is reduced by over $2.7 \mathrm{~kW}$ or 0.31 watts per square foot for that area of the sorting floor. However, with the additional lighting that was deemed necessary to fill in light due to the sulfur lamp placement, there is actually a slight increase of $0.52 \mathrm{~kW}$ or 0.06 watts per square foot for the test area.

Although it is clear that the placement of the sulfur lamp systems was not optimal, it is not known if better placement could totally eliminate the need for supplemental task lighting. The sulfur lamp systems alone provide only $77 \%$ of the original system lumen output. This may not he sufficient to light all required areas. 


\section{Electricity Supply Comparison of Pre- and Post-Retrofit Lighting Systems}

The quality of power supplied to buildings and their equipment is important with today's reliance on sensitive electronic control and application functions. Therefore, the effect any new lighting system may have on the building power supply is important to measure. For this test demonstration, power quality was measured at individual lighting circuits to obtain a general idea of the change in power quality with the Solar $1000^{\mathrm{TM}}$ lamp system. Power-supply characteristics for the pre-retrofit metal halide and F32 T8 fluorescent systems and the post-retrofit Sulfur lamp and Alto T8 fluorescent systems are shown in Table 4.

The measured power charaeteristics indicate that the Solar $1000^{\mathrm{TM}}$ systems have similar crest factor and power factor to other systems and have the lowest total harmonic distortion of all the other pre- and post-retrofit systems. Crest faetors around 1.4 to 1.5 and power factors near 1.0 are very good and have negligible effect on power quality. All of the levels of harmonic distortion are quite low, most below a current industry expectation of $20 \%$. The sulfur lamp system harmonic distortion of $3.3 \%$ is so low that it would likely not even be considered an issue with regard to most building power systems. ${ }^{3,4}$

Table 4. Pre- and Post-Retrofit Electrical Supply Characteristics

\begin{tabular}{||c|c|c|c|}
\hline Lighting Type & Crest Factor & $\begin{array}{c}\text { Total Harmonic } \\
\text { Distortion (\%) }\end{array}$ & Power Factor (\%) \\
\hline \hline \multicolumn{4}{|l||}{} \\
\hline Pre-Retrofit \\
\hline F32T8 & 1.4 & 5.1 & 1.0 \\
\hline Metal halide & 1.5 & 23.3 & 0.9 \\
\hline Post-Retrofit \\
\hline Alto T8 & 1.5 & 13.9 & 1.0 \\
\hline Solar 1000 & 1.5 & 3.3 & 1.0 \\
\hline
\end{tabular}




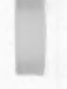

I

I

I

I

【

I

【

II

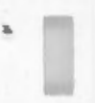

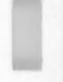

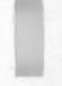

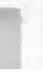




\section{Installation and Product Characteristics of the Two Systems}

The process, time, and materials required to install each of the sulfur lamp systems was an important part of this retrofit test case. Installations of equipment and lighting in sorting areas must be as efficient as possible in order to not interfere with mail operations. Mail processing is a near continuous process which in most cases may not be interrupted. Maintenance and installation typically occurs during specific process downtimes. The installation of both systems was observed and assessed to provide insight for future projects. The following are observations, suggestions, and comparisons of the installation processes.

\section{Product Integrity and Function}

- The Cylinear attachment clamp spot welds are suspect due the fact that one attachment clip was missing a spot weld. The clip was welded at the job site. The other concern is with the light tube liners. The fact that several reflective strips broke loose from the inside surface of the fixture creates concern for the quality and potential maintenance issues associated with this construction.

- The $3 \mathrm{M}$ sections are 6 feet 7 inches long as compared to the 8 foot sections of Cylinear light guide. The longer sections mean less joints, which translates to less time and labor.

- The ultrasonic welding process used on the Cylinear guides to attach the reflective strips to the inside of the guides seems to have failed. The manufacturer says that they have worked the bugs out of the welding process.

- The 3M light guide has a green tint. The Cylinear light guides have a whiter light. The Cylinear light guides apparently produce glare at the end of the guides. Postal service employees have voiced strong concerns about the excessive glare produced by the ends of the Cylinear fixtures.

- The light guide exterior cleaning seems to be an issue. The $3 \mathrm{M}$ exterior is rounded and should be easier to clean and less of a dust collection surface. The Cylinear guide presents some concern in this area due to the octagon shape with three surfaces on the top side of the guide, which act as excellent dust collection points. The wipe down or cleanup of the Cylinear guide is projected to be significantly longer. 


\section{Fixture Support}

- The marking of the ceiling for the fixture support alignment consisted of using a string line and feeding it around obstacles from a scissors lift. This method tended to lack precision and efficiency.

- The anchor installation (Hilti Drop-In Anchors) appeared to work well for this application. However, if the hole was drilled at a slight angle, the all-thread magnifies the variance. This creates significant alignment time on each run of Unistrut.

- $60-75 \%$ of the installation work and time consists of fixture support (Unistrut) Installation.

- There appeared to be no specification from the supplier for support spacing. This should be supplied to help the contractor with installation and provide loading verification.

\section{Light Guide Attachment Methods to Supports}

- $3 \mathrm{M}$ - The hanger clip installation is fairly involved with this product. The clip is attached to the Unistrut support with a bolt, spring nut, and fender washer, which keeps the clip from sucking into the Unistrut opening. This bolting process is time-consuming; however, the guide alignment is easy to achieve by utilizing this process.

- Cylinear - The attachment of the Cylinear guide support to the Unistrut is fairly easy because the clamping mechanism twists into the Unistrut with no bolting hardware required.

- An 80 foot section of $3 \mathrm{M}$ light guide took approximately 3 hours to install. The installation time was 6 hours for the same length of Cylinear product, which is apparently due to problems of achieving alignment. Even with the double installation time for the Cylinear Guide, appropriate alignment was still not achieved. Cylinear has claimed that the observed misalignment problems with their product are due to the subcontractor use of B-line instead of Unistrut support hardware. However, B-Line unistrut and Unistrut hrand strut are known as interchangeable throughout the industry and their physical dimensions are identical.

\section{Light Guide Joints}

- $3 \mathrm{M}$ - The clamping devices were a little awkward to install and in one case a proper seal could not be achieved. The possibility of dust collection inside the guide is greatly increased with the loose $3 \mathrm{M}$ fittings. $3 \mathrm{M}$ has stated that new clamping devices will be available soon, as well as the clamp used for the guide to light fixture connection. 
- Cylinear - The positive clamping device used for Cylinear light guides provides an excellent seal but has been a major problem when it comes to light guide alignment. The alignment of the light guide is critical for the proper optic reflection to take place in the guide. The guide clamps appear to cause a torque on the joints which causes a twisting of each joint which translates to misaligned guide. The hy-product is that of poor lighting levels and obvious crooked alignment.

- The manufacturers recommend that the seals not be broken on the Light guide until immediately prior to installation. The contaminants allowed into the guides can be greatly reduced by proper handling. This was not the case with this installation.

\section{Mobilization/Demobilization}

- The setup and cleanup of each day's activities requires at least 30 minutes on each end of the shift.

- Space is limited on the second floor, but all that is needed is a 4 foot by 10 foot area for the lift and tools storage area. It is estimated that the contractor will waste the equivalent of one day per week just bringing the lift and tools in and out of the facility.

- The methods used for concrete dust containment during the drilling activities for both systems were adequate and appeared to cause little or no adverse effects on existing operations. The noise generated from a Hilti Gun (if used in the future) may he significantly louder than the drilling activity and decibel limits hearing protection should be considered.

\section{Recommendations}

- Lighting retrofit projects will typically involve disposal of the existing fixtures. Disposal issues such as recycling possibilities, hazardous waste disposal, ownership/responsibility transfer points (when contractor turns fixtures over to Project Management), and staging area for materials will need to be addressed. The dust and dirt generated as a result of this activity will have a detrimental effect on equipment and overall eleanliness and must be addressed and clearly outlined in contracts. Examples: Vacuum and wipe down each existing fixture prior to demolition, or wrap each fixture in plastic and seal up prior to removal, or cover the equipment in the immediate area and take the fixtures down allowing all the dust and debris to land on the plastic for clean up. This activity has a significant cost associated with it.

- Use a stand-mounted laser for layout of support hangars. Using the same type of laser equipment used for drop ceiling installations but rotated 90 degrees, anchor locations could he marked with an extension tool. This would assure accuracy of fixture placement. The 
entire building could be laid out and marked prior to starting installation and minimize the use of lift equipment between the sorting machines.

- Using stainless aircraft cable in place of the all-thread rod could save time. The connection of the cable to the anchoring device and to the strut could be simpler. If the cable was cut to identical lengths the leveling process of the strut could be deleted, and the alignment of the strut would be easier by utilizing the free-hanging cable.

- Provide at least some laydown/setup space on the floor where the work is being done. This will reduce setup and takedown time considerably. 


\section{Occupant Survey of Pre- and Post-Retrofit Lighting Conditions}

Thirty-three people filled out the survey under the pre-retrofit conditions in June and July of 1997, and 43 under the post-retrofit conditions in August and September of 1998. Almost 68\% of the occupants were between the ages of 36 and $55,28 \%$ between 18 and 35 , and only $5 \%$ over 55 . Less than $4 \%$ of the sample reported some manner of vision impairment or color blindness (less than three people) but $83 \%$ reported wearing standard or bifocal corrective lenses.

The survey included questions on demographics, work tasks, problems related to lighting, general evaluation of lighting conditions pre and post, and ratings of the ease with which they could read sentences printed in different font sizes from $11 \mathrm{pt}$ down to $5 \mathrm{pt}$. (See the Appendix for the full survey form.)

Occupants were asked to rate how noticeable certain lighting-related characteristics were in the workspace both before and after the lighting retrofit. Ratings were given from 1 (not at all noticeable) to 4 (very noticeable). Table 5 shows the average ratings of all occupant responses to these characteristics both pre- and post-retrofit, the difference in the ratings from pre- to post-, and the typical standard deviation of responses for each item. The response differences are all very small $( \pm 0.05)$, indicating that the occupants noticed little difference. The fact that these differences are all much smaller than the standard deviation of all the responses indieates that the differences are not significant. That is, the difference is so small that it essentially represents no perceivable difference at all. However, differences with the two retrofit lighting systems were noted in the comments suhmitted with the surveys and are discussed later in this section.

Table 5. Comparison of Lighting-Related Characteristics (averages)

\begin{tabular}{||l|c|c|c|c||}
\hline \multicolumn{1}{|c|}{ Item } & Pre- Rating & Post- Rating & Difference & Standard Deviation \\
\hline \hline Reflections on screen & 1.8 & 1.7 & $\mathbf{- 0 . 1}$ & $\mathbf{0 . 8 6}$ \\
\hline Glare from ceiling lights & 2.0 & 2.0 & $\mathbf{0 . 0}$ & $\mathbf{1 . 0 8}$ \\
\hline Shadows in the task area & 2.2 & 2.0 & $\mathbf{- 0 . 2}$ & $\mathbf{1 . 0 5}$ \\
\hline Noise from light fixtures & 1.2 & 1.2 & $\mathbf{0 . 0}$ & $\mathbf{. 5 4}$ \\
\hline Flicker from lights & 1.6 & 1.3 & $\mathbf{- 0 . 3}$ & $\mathbf{. 8 2}$ \\
\hline Too much heat from lights & 1.9 & 1.5 & $\mathbf{- 0 . 4}$ & $\mathbf{1 . 0}$ \\
\hline Inability to control lighting & 2.6 & 2.1 & $\mathbf{- 0 . 5}$ & $\mathbf{1 . 3 1}$ \\
\hline Lighting looks unnatural & 1.9 & 2.2 & $\mathbf{0 . 3}$ & $\mathbf{1 . 1 8}$ \\
\hline Lack of light where needed & 2.4 & 2.4 & $\mathbf{0 . 0}$ & $\mathbf{1 . 1 4}$ \\
\hline
\end{tabular}


Occupants were also asked to rate how easy or difficult it was to read four different size font sentences under each set of lighting conditions. Table 6 presents a comparison of these responses. As with the responses to lighting characteristics there appears to be little difference in the occupants ability to read the given sentences. There is a slight preference for the retrofit sulfur lighting systems when reading the smallest font sentence (tiny font $-5 \mathrm{pt}$ ) but the difference is still smaller than the standard deviation.

Occupants were also asked for their overall impression of the pre- and post-retrofit lighting. Table 7 presents these average responses. This time, the occupant responses were separated by the retrofit sulfur lamp system they worked the most under. Again, the small differences compared to the standard deviation indicates no perceivable difference between pre- and postlighting.

Occupants were also encouraged to provide any feedback concerning the change in lighting in their workspace. A variety of responses were received including some that were not specifically related to lighting or the spaces that underwent a lighting change and some that appeared to be in jest (placed at the end of the list). All of the responses are included here (including those with suspect sincerity) to provide the site with information on all of the concerns the occupants surveyed appeared to have at the time. One noticeable trend in several of the comments is the "blinding glare" that is evident when looking towards the ends of the Cylinear (hex shaped) light guide system. Conversations with some occupants confirmed this effect that was not evident with the $3 \mathrm{M}$ system.

Table 6. Comparison of Sentence Readability (averages)

\begin{tabular}{||l|c|c|c|c||}
\hline \multicolumn{1}{|c|}{ Sentence } & Pre-Rating & Post-Rating & Difference & $\begin{array}{c}\text { Standard } \\
\text { Deviation }\end{array}$ \\
\hline \hline Large $(11 \mathrm{pt})$ & 6.5 & 6.2 & $\mathbf{- 0 . 3}$ & $\mathbf{1 . 4}$ \\
\hline Medium $(9 \mathrm{pt})$ & 5.7 & 5.7 & $\mathbf{0 . 0}$ & $\mathbf{1 . 5}$ \\
\hline Small $(7 \mathrm{pt})$ & 4.5 & 4.9 & $\mathbf{0 . 4}$ & $\mathbf{1 . 8}$ \\
\hline Tiny $(5 \mathrm{pt})$ & 2.3 & 3.3 & $\mathbf{1 . 0}$ & $\mathbf{2 . 0}$ \\
\hline
\end{tabular}

Table 7. Overall Satisfaction Comparison (averages)

\begin{tabular}{||l|c|c|c|c||}
\hline $\begin{array}{c}\text { Primary Retrofit Work } \\
\text { Lighting }\end{array}$ & Pre-Rating & Post-Rating & Difference & $\begin{array}{c}\text { Standard } \\
\text { Deviation }\end{array}$ \\
\hline \hline Cylinear & 2.9 & 2.6 & $\mathbf{- 0 . 4}$ & $\mathbf{1 . 1}$ \\
\hline $3 \mathrm{M}$ & 2.9 & 2.7 & $\mathbf{- 0 . 3}$ & $\mathbf{1 . 1}$ \\
\hline
\end{tabular}




\section{Comments}

- We have no direct overhead lighting in the new patching area between $19 \mathrm{~F}$ and the wall which would be $20 \mathrm{~F}$.

- The current lighting causes me considerable glare headaches. Almost everyday after 3.5-5 hours.

- There is too much dust in the workroom floor.

- The lighting system is fairly well we do of course need a better AC to deal with the heat and extra heating from lights.

- Some column areas lit much better than other columns. $6 \mathrm{G} \& 7 \mathrm{~J}$ are especially in need of better light. By the way, when is the $\mathrm{AC}$ going to be fixed?

- Of all the lighting aspects I have in contact with, it seem that the best most represents the sun natural spectrum; there is always some hue or light quality missing in artificial.

- The area over part of the "Flats" needs better lighting. The DRIS areas surrounding 51, 50 machines are too "hot" need Fans! Soon! For the workers. Thank you.

- Most of the lights are between the machines not over them.

- Lighting on machines varies tremendously. I prefer working under bright lights. Some machines have very poor and dim lighting. This puts tremendous strain on my eyes.

- Relocate the lighting (or machines) so they work in conjunction and not at different locations.

- Some work areas do not have any lighting overhead at all.

- It's hard to read in here when casing letters! If I was blind I would still have a hard time reading in this place!

- I DO NOT LIKE blue white light causes me eye strain and headaches.

- Not all the shadows are caused by the new lighting. There are places where additional lighting is needed or overhead obstruction causes shadows. 
- I prefer fluorescent lighting. I feel this provides the brightest light.

- I prefer brightly lit. Dust levels very irritating to my respiratory system. Congestion levels unsafe and impede production.

- TOO MUCH GLARE!!

- Hexagonal tube slightly blinds you when you have to walk from one end of the machine to the other.

- The existing lighting we have had for years is much better to work under.

- Hexagonal light uneven. Quality of light from round tube is superior but individual halide is better for overall coverage. Hexagonal tube is very bad - uneven and glare.

- A lot of dust, I knew its been mentioned but seems to make allergy act up. Mask really don't help. Please help with the dust.

- The new lighting is not efficient. Very ineffective, should be removed. Fluorescent tube are back up to light pipe. Which should be the case if pipe is working?

- The hexagonal tube is terribly inadequate!! It concentrates its brightness at the end creating a glare which is blinding if you are near the ends.

- Hexagonal tube make things look depressing (the color green/gray) dingy sick.

- Help get me out of here!

- I have started growing a tail and my eyes glow at night since the installation of the new lights.

- I have had 2 cancerous tumors removed from my brain since the new lighting was installed. Please remove it immediately. 


\section{References}

1. Dolan, J.T., M.G. Ury, and C.H. Wood. "A Novel High Efficiency Microwave Powered Light Source." Presented as a landmark paper September 2, 1992, Sixth International Symposium on the Science and Technology of Light Sources at the Technical University of Budapest.

2. Hollow Light Guide Applications. CIE Technical Committee TC 3-30, Vol. I, March 1995, "Brief History of Illumination With Hollow Light Guides," p. 3.

3. Specifier Reports. National Lighting Product Information Program, Vol. 1, issue 6, April 1993, "Screwhase Compact Fluorescent Lamp Products," p. 5.

4. Lighting Answers. National Lighting Product Information Program, Vol. 2, Number 2, February 1995, "Power Quality." 



\section{Appendix}

Lighting Survey Questionnaires 


\section{Processing and Distribution Center $2^{\text {nd }}$ Floor Lighting Study}

\section{BACKGROUND INFORMATION:}

Age group: $\square$ 18-25 $\square$ 26-35 $36-45 \square$ 46-55 $\square$ over 55

Gender: $\square \mathrm{M} \square \mathrm{F} \quad$ To your knowledge are you colorblind/color deficient? $\square$ Y $\square \mathrm{N}$

Which type of overhead lighting (main lighting, not task lights) do you currently work under?

Fluorescent tube strip fixtures $\square$ Metal Halide individual fixtures

At work do you normally wear:

$\square$ Contacts? $\square$ Standard Lens Eyeglasses? $\square$ Bifocals? $\square$ Trifocals?

Do you have cataracts or other vision impairments that currently effect your vision?

$\square \mathrm{Y} \square \mathrm{N}$ IF YES, please describe:

\section{SPECIFIC LIGHTING EVALUATION QUESTIONS:}

Listed below are characteristics of lighting systems that people may notice in their work place. For each one, please rate how noticeable these are to you in your workplace.

Reflections on the computer screen

Glare or too much light from ceiling lights

Shadows in the task area

Noise from the light fixtures

Flicker from the overhead lights

Too much heat from the lights

Inability to control the lighting

Lighting makes colors look unnatural

Light not available where it is needed

Other:
Not

At All

$\square$

$\square$

$\square$

$\square$

$\square$

$\square$

$\square$

$\square$

$\square$

$\square$
Somewhat

Moderately

Very

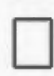

$\square$

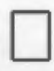

$\square$

$\square$

$\square$

$\square$

$\square$

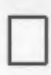

$\square$

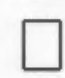

Much

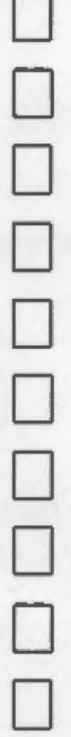




To what extent does your job require you to:
Read paper manuals or texts?
Distinguish between different colors?
Move around in confined spaces?
View things from awkward angles?
Read small print?

Please use the following 7-point scale to indicate how easy or difficult it is to read each of the four sentences /while standing under your workplace lighting/.

While other plants put the sun's energy to work, the fungus
must look elsewhere
The end result of this project will be a sky atlas that includes 1,870
photographs of celestial bodies and their statistics.
Whenever you see a pile of leaves tuming to compost, you are watching a fungus eating.
The fungus has become the eanh's scavenger.

How would you rate the overall current lighting in your workplace?

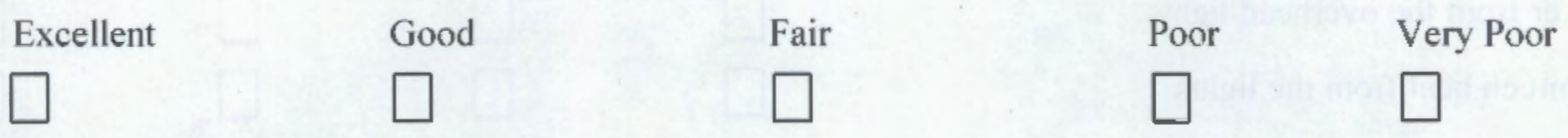

Are there any other comments you would like to make about the lighting or other aspects of the environment that we have not asked about? 
Please fill in the last four digits of your social security number:

This information cannot and will not be used to identify you; it will be available only to the research team at PNNL (not associated with the USPS) and will only be used for matching your responses between the first (before retrofit) and second (after retrofit) lighting surveys.

Please place this completed survey in the self-addressed postage-paid envelope provided and place in the mail.

\section{Thank you for your help.}





\section{Processing and Distribution Center $2^{\text {nd }}$ Floor Lighting Study [AFTER LIGHTING RETROFIT OF COLUMNS 10 - 12]}

\section{BACKGROUND INFORMATION:}
Age group:
$18-25$
26-35
$36-45$
$46-55$
over 55

Gender: $\square \mathrm{M} \square \mathrm{F} \quad$ To your knowledge are you colorblind/color deficient? $\square \mathrm{Y} \square \mathrm{N}$

What portion of the workday do you spend working under each of the NEW lighting systems:
Round tube (Col. 11- 12)?
$\square$ Little/None $\square$ 1/4
$\square 1 / 2$
$\square 3 / 4$
$\square$ Most/All
Hexagonal tube (Col. 10 - 11)?
$\square$ Little/None $\square 1 / 4$
$1 / 2$
\3/4
Most/All

Which type of overhead lighting (main lighting, not task lights) did you work under before the retrofit?

$\square$ Fluorescent tube strip fixtures

Metal Halide individual fixtures

At work do you normally wear:

$\square$ Contacts? $\square$ Standard Lens Eyeglasses? $\square$ Bifocals? $\square$ Trifocals?

Do you have cataracts or other vision impairments that currently effect your vision?

$\square \mathrm{Y} \square \mathrm{N}$ IF YES, please describe:

\section{SPECIFIC LIGHTING EVALUATION QUESTIONS:}

Listed below are characteristics of lighting systems that people may notice in their work place. For each one, please rate how noticeable these are to you in your workplace.

Reflections on the computer screen
Glare or too much light from ceiling lights
Shadows in the task area
Noise from the light fixtures
Too much heat from the lights
Lighting makes colors look unnatural
Other:


To what extent does your job require you to:

Read paper manuals or texts?

Distinguish between different colors?

Moderately

Much

Move around in confined spaces?

View things from awkward angles?

Read small print?
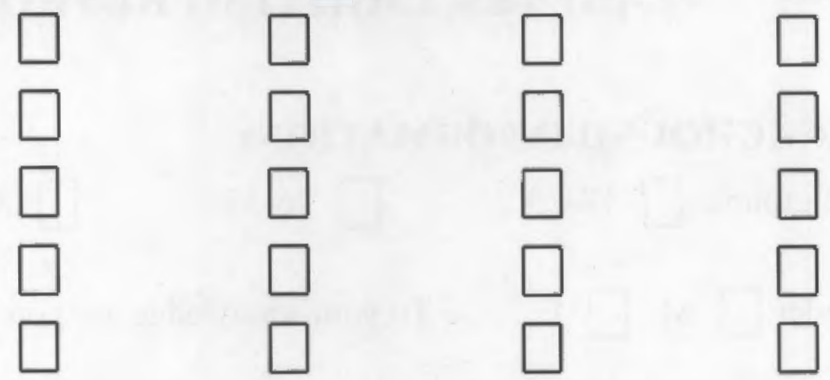

Please use the following 7-point scale to indicate how easy or difficult it is to read each of the four sentences Iwhile standing under your workplace lightingl.

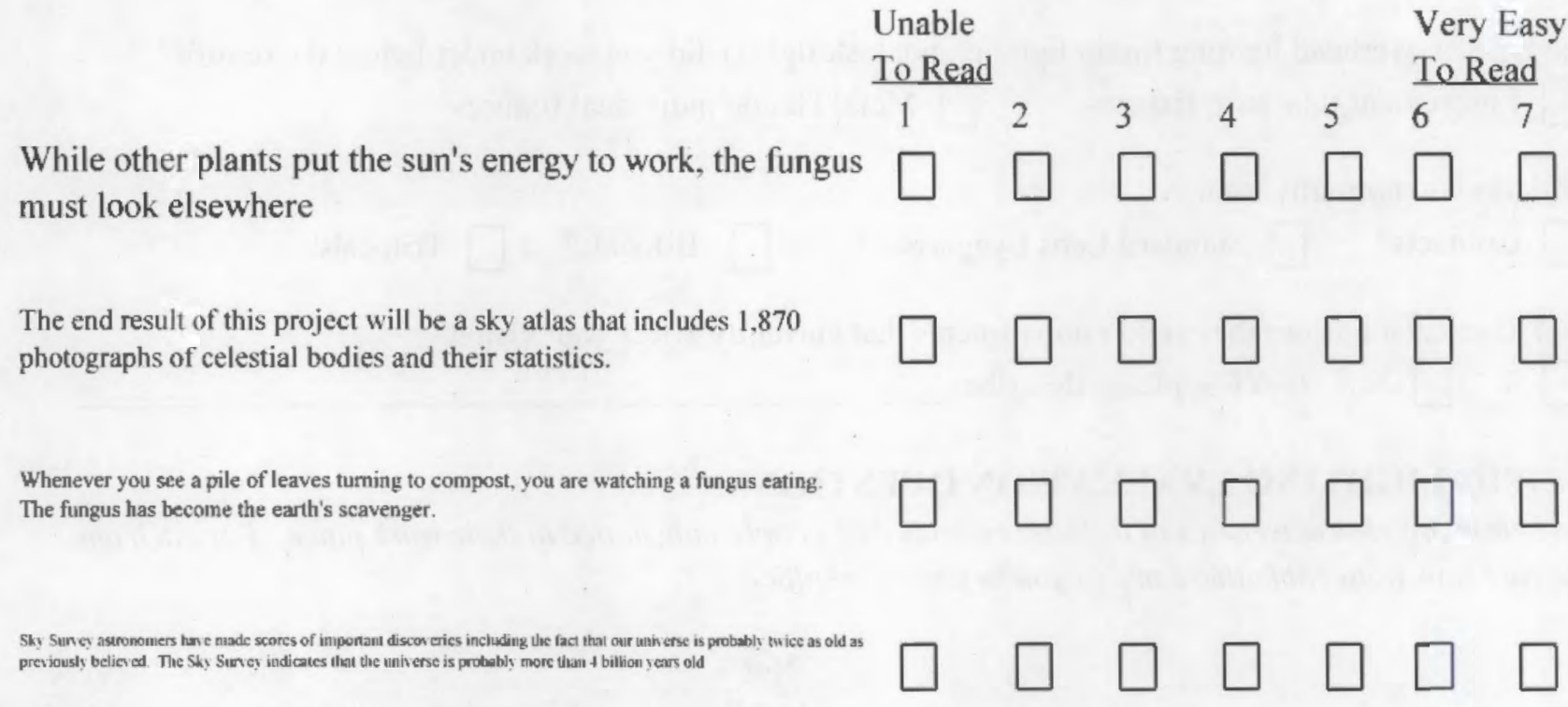

How would you rate the overall current (NEW) lighting in your workplace?

Round tube (Col. 11 - 12)?

Excellent<smiles>C1CCC1</smiles>

Good

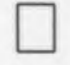

Fair<smiles>C1CCC1</smiles>

Fair
Poor
$\square$

Poor
Very Poor<smiles>C1CCC1</smiles>

Hexagonal tube (Col. 10 - 11)?

Excellent

Good

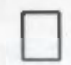

Very Poor 
Are there any other comments you would like to make about the NEW or old lighting or other aspects of the environment that we have not asked about?

Please fill in the last four digits of your social security number:

This information cannot and will not be used to identify you; it will be available only to the research team at PNNL (not associated with the USPS) and will only be used for matching your responses between the first (before retrofit) and second (after retrofit) ligbting surveys.

Please place this completed survey in the self-addressed postage-paid envelope provided and place in the mail.

\section{Thank you for your help.}



PNNL-12224

\section{Distribution}

No. of

Copies

OFFSITE

2 DOE/Office of Scientific and Technical Information

3 U.S. Department of Energy

Federal Energy Management Program 1000 Independence Avenue, SW

Washington, DC 20585

ATTN: T. Collins
A. S. Crawley
S. Fidler

W. Carroll

Lawrence Berkeley National Laboratory

One Cyclotron Road

Berkeley, CA 94720

12 L. W. Fish

U.S. Postal Service

P.O. Box 4009

Portland, OR 97208-4009

P. Garland

Oak Ridge National Laboratory

600 Maryland Avenue, SW, Suite 306W

Washington, DC 20024

2 M. H. Grey

U.S. Postal Service

P.O. Box 3099

Portland, OR 97208-3099
No. of

Copies

5 C. Merwin

Portland General Electric

121 Salmon Street, 1WTC0706

Portland, OR 97204

R. Parish

National Renewable Energy Laboratory

1617 Cole Boulevard, MS 2723

Golden, CO 80401-3393

\section{ONSITE}

DOE Richland Operations Office

D. Biancosino

K8-50

25 Pacific Northwest National Laboratory

M. L. Bruun

P7-63

S. A. Parker (5)

K5-08

D. R. Payson

K 7-90

E. E. Richman (10)

K5-16

W. F. Sandusky

K5-08

FEMP Project File (2)

Technical Report Files (5)

Distr.1 
